\title{
BMJ Open Characteristics of young children with developmental delays and their trends over 14 years in Taiwan: a population- based nationwide study
}

Der-Chung Lai, ${ }^{1,2}$ Yen-Cheng Tseng, ${ }^{3}$ How-Ran Guo ${ }^{4,6,5}$ Guo H-R. Characteristics of young children with their trends over 14 years in Taiwan: a population-based nationwide study. BMJ Open 2018;8:e020994. doi:10.1136/ bmjopen-2017-020994

- Prepublication history for this paper is available online. To view these files, please visit the journal online (http://dx.doi. org/10.1136/bmjopen-2017020994).

Y-CT and H-RG contributed equally.

Received 5 December 2017 Revised 16 February 2018 Accepted 20 February 2018
To cite: Lai D-C, Tseng Y-C, developmental delays and

\section{ABSTRACT}

Objectives To describe the epidemiological characteristics of developmental delays (DD) at the national level and assess the changes over time.

Design We calculated the incidence rates of DD from 2003 to 2016 and assessed the trends over time.

Setting As dictated by law, local governments in Taiwan are required to register children with $\mathrm{DD}$ and provide services. The central government has constructed a national registry with the data from local centres. We analysed the national registry data.

Participants We included children who were under 6 years old, and this population ranged from 1164150 to 1577443 per year during the study period. All registered cases were certified through a process set forth by law.

Primary and secondary outcome measures We calculated annual incidence rates by age, sex and geographical area, and assessed trends over the study period.

Results The incidence of DD in children under 6 years old displayed an increasing trend over the study period, ranging from 7.0 to 16.3 per 1000 person-years. Boys had higher incidence throughout all 14 years, and the boy-to-girl rate ratios had an increasing trend over time with some fluctuations, ranging from $1.84(95 \% \mathrm{Cl} 1.77$ to 1.92 ) to 1.99 (95\% Cl 1.93 to 2.06$)$. In addition, rural areas had higher incidence rates, and the rural to urban rate ratios ranged from $0.98(95 \% \mathrm{Cl} 0.94$ to 1.03$)$ to 2.00 (95\% Cl 1.94 to 2.06) without apparent time trends. Girls had a higher proportion of early reporting ( $<3$ years) throughout all years, but the differences in the proportion of early reporting between rural and urban areas were not consistent.

Conclusions Male sex appeared to be a risk factor for $\mathrm{DD}$, which is unlikely to be due to more attention received by boys because girls had a higher proportion of early reporting. We also found that children lived in rural areas appeared to have a higher risk of having DD.

\section{INTRODUCTION}

For numbered affiliations see end of article.

Correspondence to Professor How-Ran Guo; hrguo@mail.ncku.edu.tw
Developmental delays (DD) are generally defined as a child does not reach expected developmental milestones at the age. ${ }^{1}$ Although DD are prevalent among children, data on its incidence at the national level are

\section{Strengths and limitations of this study}

- The Taiwanese registry of children with developmental delays includes only new cases, which provides incidence data that are rarely available at the national level.

- The law in Taiwan mandates the reporting of cases, which minimises under-reporting.

- Using nationwide registry data, this study has a large sample size, with a population of more than one million each year.

- The duration of data collection in this study was 14 years, and the assessment of time trends over such a long period of time at the national level has rarely been achieved in previous studies.

- The major limitation of our study is that the government does not release data on individual cases, which make it impossible to conduct the analysis in further detail.

limited. For the identification of risk factors, incidence data are generally more useful than prevalence data. However, the majority of previous studies on DD used prevalence data, most likely because incidence data were more difficult to obtain. ${ }^{2}$ As a result, changes in epidemiological characteristics over time are seldom assessed, because such studies would require incidence data.

A child's development is affected by many biological and environmental factors. ${ }^{1}$ Among biological ones, male sex is a strong risk factor. ${ }^{3}$ Many studies found that the prevalence rate for DD was higher in boys than in girls. ${ }^{34}$ Also, residents of rural areas have reported more health-related problems than those of urban areas in general, ${ }^{5}$ and this disparity might also be true for DD. However, studies on this topic are limited and have reported inconsistent results. For example, the Multiple Indicator Cluster Survey conducted by the United Nations Children's Fund in countries with low and middle incomes did not observe consistent results in 
terms of differences between rural and urban areas across various countries. ${ }^{6}$

Under the Children Welfare Law, local governments in Taiwan have established Early Intervention Reporting and Referral Centers (EIRRCs) to register and provide services to children with DD. ${ }^{7}$ The Children and Youth Welfare Law also mandates that institutions of welfare, education and medicine report all children with suspected DD to the EIRRC. ${ }^{8}$ Using data collected at the EIRRCs, the central government has constructed a national registry of children with DD. This registry provides researchers with a unique resource with which to conduct nationwide epidemiological studies. In a previous study, we analysed the national registry data from 2003 to 2008 . $^{2}$ However, since it is difficult to precisely evaluate the trends of incidence with only 6 years' worth of data, we extended the time range from 2003 to 2008 to a 14-year period until 2016 as more data became available. This better suited our purposes of studying epidemiological characteristics of incident cases of DD and assessing time trends.

\section{METHODS}

\section{Case definition}

The Enforcement Rules of the Children and Youth Welfare Law of Taiwan ${ }^{9}$ defined DD as 'allegedly or expected abnormal development in respect of cognitive development, physiological development, language and communication development, psycho-social development or self-governing skills that have been judged and confirmed by the accredited medical institutes under health authority.' In order to be registered as a case of $\mathrm{DD}$, the child requires an assessment performed by a physician at an accredited hospital or by a trained social worker in an EIRRC, ${ }^{10}$ who generally used the Taipei City Developmental Checklist for Preschoolers, Second Version as the assessment tool. ${ }^{11}$

\section{Data collection}

The EIRRCs collect data on newly reported cases and report such cases to the central government, which maintains a registry of cases and publishes a yearbook each year. Before the reorganisation of the government in 2013, the registry was maintained by the Ministry of the Interior. After 2013, this responsibility fell to the Ministry of Health and Welfare. This yearbook includes the total numbers of newly reported cases by age at reporting, sex and area. ${ }^{12}$ We analysed the data from 2003 to 2016.

We divided the cases into two groups, <3 years and $3-5$ years, according to the age at the time of reporting and defined the group $<3$ years as 'early reporting'. ${ }^{13}$ Although the yearbook includes statistics on an age group ' $\geq 6$ years,' we did not include this group in our analyses because it only includes children who have not yet entered the primary school, not all children who are 6 years of age or older.

In the stratified analyses by geographical area, we divided the administrative regions in Taiwan into two groups: 'urban areas' and 'rural areas.' An urban area is one in which more than $50 \%$ of the population live in metropolitan areas (as defined by the Directorate-General of Budget, Accounting and Statistics of Taiwan). ${ }^{14}$ Consequently, a rural area is one in which $50 \%$ or less of the population live in metropolitan areas. In a reorganisation of administrative regions in 2011, the original Tainan City (an urban area) and Tainan County (a rural area) were merged into the new Tainan City. Data on the two original administrative regions have been unavailable since this merging, so they were both excluded from this part of the analyses.

To calculate incidence rates, we obtained data on the numbers of boys, girls and the total population in each age group for each administrative region from the Monthly Bulletin of Interior Statistics. ${ }^{15}$

\section{Data analysis}

We estimated age-specific incidence rates in a given year by dividing the number of newly reported cases by the number of individuals in a specific age group. Likewise, the sex-specific incidence rates of each year were estimated by dividing the number of newly reported cases by the number of individuals of each sex. We evaluated the differences between the two sexes by using the incidence rate ratio calculated through dividing the incidence rate in boys by the incidence rate in girls. To evaluate the geographical differences, we estimated the incidence rate in rural or urban areas in each year by first dividing the number of newly reported cases by the number of individuals in each type of area and then obtaining the incidence rate ratio by dividing the incidence rate in rural areas by the incidence rate in urban areas. A 95\% CI was constructed for each rate ratio to evaluate its statistical significance.

To evaluate the difference in early reporting between boys and girls, we calculated the proportion of early reporting in boys or girls each year by dividing the number of cases under 3 years of age by the number of cases under 6 years of age in each sex. We then obtained the boy-to-girl proportion ratio of early reporting by dividing the proportion in boys by the proportion in girls. A $95 \%$ CI was constructed for each proportion ratio to evaluate its statistical significance.

Likewise, to evaluate the difference of early reporting between rural and urban areas, we calculated the proportion of early reporting in rural or urban areas in each year by dividing the number of cases under 3 years of age by the number of cases under 6 years of age in each area. We then obtained the rural to urban proportion ratio of early reporting by dividing the proportion in rural areas by the proportion in urban areas. A 95\% CI was constructed for each proportion ratio to evaluate its statistical significance.

We reported descriptive statistics as numbers or percentages and used linear regressions to evaluate the trends of changes in incidence rates, incidence rate ratios and proportion ratios over time. All the analyses were conducted using SAS V.9.1, and all the statistical 
Table 1 Overall incidence rate of developmental delays in children under 6 years of age

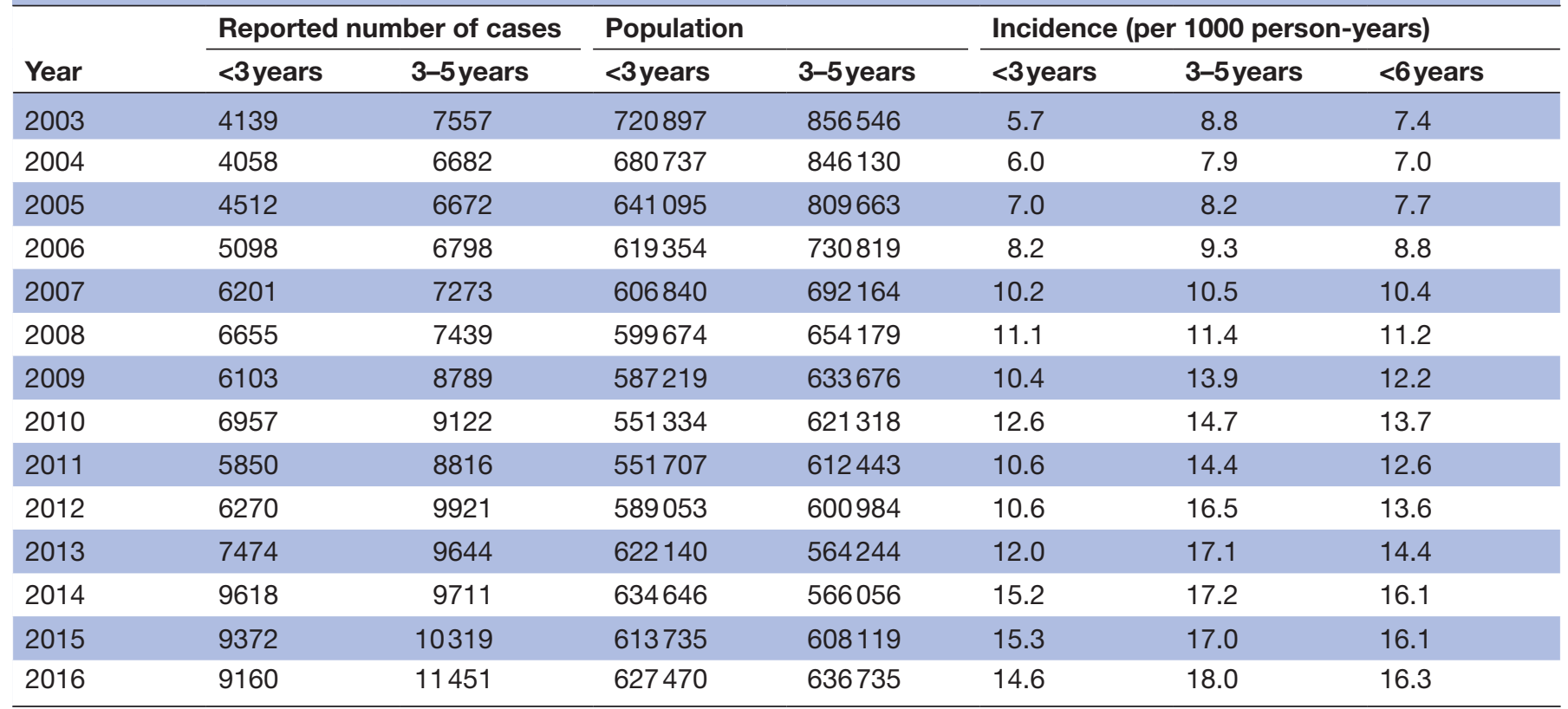

tests were performed at the two-tailed significance level of 0.05 .

\section{RESULTS}

During the study period of 2003-2016, 211661 new cases of DD under 6 years of age were registered, and the overall incidence rate was from 7.0 to 16.3 per 1000 person-years. The rate was from 5.7 to 15.3 per 1000 person-years in children under 3 years of age and 7.9 to 18.0 per 1000 person-years in children 3-5 years of age. We observed a general increasing trend over time in all three age groups $(\mathrm{p}<0.01$ for all) (table 1$)$.

With data on 14 years, we were able to compare the incidence among four mutually exclusive birth cohorts. Using the 2001-2003 cohort (those who were in the $<3$ years group in 2003) as the baseline, we observed an increasing trend in the estimated overall incidence rates in children under 6 years old. Specifically, the estimated overall incidence rate before 6 years of age was 7.5 per 1000 in the 2001-2003 birth cohort, 11.1 per 1000 in the 2004-2006 birth cohort, 13.5 per 1000 in the 2007-2009 birth cohort and 13.9 per 1000 in the 2010-2012 birth cohort. The trend was similar to that observed in the year-by-year overall incidence rates.

The overall incidence rate ranged from 9.0 to 21.3 per 1000 person-years in boys and from 4.9 to 11.0 per 1000 person-years in girls. The rate was constantly higher in boys than in girls, and the boy-to-girl rate ratios had an increasing trend over time $(\mathrm{p}<0.01)$ with some fluctuations, ranging from 1.84 to 1.99 (table 2). All the rate ratios were statistically significant.

With the exclusion of Tainan City and County, there were 6 cities and 17 counties in Taiwan. All six cities and 5 of the 17 counties were classified as urban areas, and the remaining 12 counties were classified as rural areas. The overall incidence rate ranged from 7.2 to 25.5 per 1000 person-years in rural areas and from 6.1 to 14.7 per 1000 person-years in urban areas. The incidence rates were generally higher in rural than in urban areas, except for the year 2003, in which the rural to urban rate ratio was not statistically significant (table 3 ). In other years, the ratio fluctuated from 1.10 to 2.00 and all reached statistical significance. There was no apparent trend in the changes over time.

The proportion of early reporting had an increased trend from 2003 to 2008 and then showed fluctuations afterwards (table 4). Girls had a higher proportion of early reporting than boys throughout all years, with the boy-to-girl proportion ratios ranging from 0.85 to 0.94. All the proportion ratios were statistically significant, but there was no apparent trend in the changes over time. The difference in the proportion of early reporting between rural and urban areas fluctuated over time. The rural to urban proportion ratios ranged from 0.79 to 1.19 , and there was no apparent trend in the changes over the years (table 5).

\section{DISCUSSION}

The overall incidence rate of DD in children under 6 years of age generally increased during the study period, which is consistent with the observation in our preliminary study. ${ }^{2}$ We believe the increase cannot be attributed to an increase in the number of cases, because the major risk factors for DD such as genetic constructs, medical care and socioeconomic status ${ }^{116}$ did not undergo remarkable changes over the 14 year period. In fact, there were no changes in the diagnostic and reporting criteria of DD, neither. Therefore, the 
Table 2 Overall incidence rate and rate ratio of developmental delays in children under 6 years of age by sex

\begin{tabular}{|c|c|c|c|c|c|c|c|}
\hline \multirow[b]{2}{*}{ Year } & \multicolumn{2}{|c|}{$\begin{array}{l}\text { Reported number of } \\
\text { cases }\end{array}$} & \multicolumn{2}{|c|}{ Population } & \multicolumn{2}{|c|}{$\begin{array}{l}\text { Incidence } \\
\text { (per } 1000 \text { person-years) }\end{array}$} & \multirow[b]{2}{*}{ Rate ratio $(95 \% \mathrm{Cl})$} \\
\hline & Boy & Girl & Boy & Girl & Boy & Girl & \\
\hline 2003 & 7837 & 3859 & 823435 & 754008 & 9.5 & 5.1 & $1.86(1.79 \text { to } 1.93)^{*}$ \\
\hline 2004 & 7183 & 3557 & 797949 & 728918 & 9.0 & 4.9 & $1.84(1.77 \text { to } 1.92)^{\star}$ \\
\hline 2005 & 7550 & 3634 & 758014 & 692744 & 10.0 & 5.2 & $1.90(1.83 \text { to } 1.98)^{*}$ \\
\hline 2006 & 7998 & 3898 & 705549 & 644624 & 11.3 & 6.0 & $1.87(1.80 \text { to } 1.95)^{\star}$ \\
\hline 2007 & 9053 & 4421 & 679395 & 619609 & 13.3 & 7.1 & $1.87(1.80 \text { to } 1.94)^{\star}$ \\
\hline 2008 & 9463 & 4631 & 655736 & 598117 & 14.4 & 7.7 & $1.86(1.80 \text { to } 1.93)^{\star}$ \\
\hline 2009 & 9981 & 4911 & 637773 & 583122 & 15.6 & 8.4 & $1.86(1.80 \text { to } 1.92)^{*}$ \\
\hline 2010 & 10968 & 5111 & 612072 & 560580 & 17.9 & 9.1 & $1.97(1.90 \text { to } 2.03)^{\star}$ \\
\hline 2011 & 9969 & 4697 & 607034 & 557116 & 16.4 & 8.4 & 1.95 (1.88 to 2.02$)^{*}$ \\
\hline 2012 & 11069 & 5122 & 619396 & 570641 & 17.9 & 9.0 & $1.99(1.93 \text { to } 2.06)^{\star}$ \\
\hline 2013 & 11578 & 5540 & 616451 & 569933 & 18.8 & 9.7 & $1.93(1.87 \text { to } 1.99)^{*}$ \\
\hline 2014 & 13122 & 6207 & 622626 & 578076 & 21.1 & 10.7 & $1.96(1.90 \text { to } 2.02)^{\star}$ \\
\hline 2015 & 13419 & 6272 & 633460 & 588394 & 21.2 & 10.7 & $1.99(1.93 \text { to } 2.05)^{*}$ \\
\hline 2016 & 13939 & 6672 & 654986 & 609219 & 21.3 & 11.0 & $1.94(1.89 \text { to } 2.00)^{\star}$ \\
\hline
\end{tabular}

${ }^{*} \mathrm{P}<0.05$.

increased incidence rate of DD is more likely to be due to the improvement in reporting of cases, which may be in turn attributable to the improvement in the awareness of the developmental abnormalities in children, lower discrimination against the patients, better service of the related agencies, more willingness demonstrated by parents and guardians to register their children and so on. ${ }^{17} 18$ These were generally gradual changes, and therefore we did not observe any abrupt changes in the incidence of DD over time, indicating the lack of an obvious period effect.

In addition to cases confirmed by physicians, the registry also includes cases identified by trained social workers in the EIRRCs. This would lead to overestimation of the incidence rates. However, the registry ascertains cases through reporting rather than thorough

Table 3 Overall incidence rate and rate ratio of developmental delays in children under 6 years of age by areat

\begin{tabular}{|c|c|c|c|c|c|c|c|}
\hline \multirow[b]{2}{*}{ Year } & \multicolumn{2}{|c|}{ Reported number of cases } & \multicolumn{2}{|c|}{ Population } & \multicolumn{2}{|c|}{$\begin{array}{l}\text { Incidence } \\
\text { (per } 1000 \text { person-years) }\end{array}$} & \multirow[b]{2}{*}{ Rate ratio $(95 \% \mathrm{Cl})$} \\
\hline & Rural & Urban & Rural & Urban & Rural & Urban & \\
\hline 2003 & 3016 & 7651 & 417597 & 1041508 & 7.2 & 7.3 & 0.98 (0.94 to 1.03$)$ \\
\hline 2004 & 3499 & 6161 & 401360 & 1010972 & 8.7 & 6.1 & $1.43(1.37 \text { to } 1.49)^{\star}$ \\
\hline 2005 & 3275 & 7031 & 379954 & 962324 & 8.6 & 7.3 & $1.18(1.13 \text { to } 1.23)^{*}$ \\
\hline 2006 & 3401 & 7580 & 350937 & 898852 & 9.7 & 8.4 & $1.15(1.10 \text { to } 1.20)^{\star}$ \\
\hline 2007 & 3688 & 8794 & 331562 & 871125 & 11.1 & 10.1 & $1.10(1.06 \text { to } 1.14)^{\star}$ \\
\hline 2008 & 4843 & 8177 & 312880 & 847893 & 15.5 & 9.6 & $1.61(1.55 \text { to } 1.66)^{\star}$ \\
\hline 2009 & 4306 & 9515 & 298839 & 831537 & 14.4 & 11.4 & $1.26(1.22 \text { to } 1.31)^{*}$ \\
\hline 2010 & 5108 & 9881 & 280108 & 806265 & 18.2 & 12.3 & $1.49(1.44 \text { to } 1.54)^{\star}$ \\
\hline 2011 & 5074 & 8779 & 268296 & 808844 & 18.9 & 10.9 & $1.74(1.68 \text { to } 1.80)^{\star}$ \\
\hline 2012 & 5829 & 9336 & 266682 & 833418 & 21.9 & 11.2 & $1.95(1.89 \text { to } 2.02)^{\star}$ \\
\hline 2013 & 5339 & 10124 & 261442 & 835199 & 20.4 & 12.1 & $1.68(1.63 \text { to } 1.74)^{\star}$ \\
\hline 2014 & 6629 & 10838 & 259828 & 850302 & 25.5 & 12.7 & $2.00(1.94 \text { to } 2.06)^{\star}$ \\
\hline 2015 & 5531 & 12576 & 257152 & 872878 & 21.5 & 14.4 & $1.49(1.45 \text { to } 1.54)^{\star}$ \\
\hline 2016 & 5591 & 13365 & 261055 & 908526 & 21.4 & 14.7 & $1.46(1.41 \text { to } 1.50)^{*}$ \\
\hline
\end{tabular}

${ }^{*} \mathrm{P}<0.05$.

†Tainan City and Tainan County were excluded in the analyses due to a reorganisation of administrative regions in 2011. 
Table 4 Proportion of early reporting of developmental delays in children under 6 years of age by sex

\section{Reported number of cases}

Total

\section{rom years}

$<3$ years

Year < 3 years < 6 years (\%)

$\begin{array}{llll}2003 & 4139 & 11696 & 35.4\end{array}$

$\begin{array}{llll}2004 & 4058 & 10740 & 37.8\end{array}$

$\begin{array}{llll}2005 & 4512 & 11184 & 40.3\end{array}$

$\begin{array}{llll}2006 & 5098 & 11896 & 42.9\end{array}$

$\begin{array}{llll}2007 & 6201 & 13474 & 46.0\end{array}$

$\begin{array}{llll}2008 & 6655 & 14094 & 47.2\end{array}$

$\begin{array}{llll}2009 & 6103 & 14892 & 41.0\end{array}$

$\begin{array}{llll}2010 & 6957 & 16079 & 43.3\end{array}$

$\begin{array}{llll}2011 & 5850 & 14666 & 39.9\end{array}$

$\begin{array}{llll}2012 & 6270 & 16191 & 38.7\end{array}$

$\begin{array}{llll}2013 & 7474 & 17118 & 43.7\end{array}$

$\begin{array}{llll}2014 & 9618 & 19329 & 49.8\end{array}$

20159372

20169160

$20611 \quad 44.4$

\section{Boy}

$<3$ years <6years $(\%)$

$\begin{array}{lll}2660 & 7837 & 33.9\end{array}$

$2648 \quad 7183 \quad 36.9$

$2881 \quad 7550 \quad 38.2$

$3321 \quad 7998 \quad 41.5$

$\begin{array}{lll}3953 & 9053 \quad 43.7\end{array}$

4310

3995

4627

3896

4153

4818

6320

6066

5944

$9463 \quad 45.5$

$9981 \quad 40.0$

$10968 \quad 42.2$

$9969 \quad 39.1$

$11069 \quad 37.5$

$11578 \quad 41.6$

$13122 \quad 48.2$

$13419 \quad 45.2$

$13939 \quad 42.6$

${ }^{*} \mathrm{P}<0.05$.

active screenings in the communities or schools, and therefore the candidates who receive the screening generally have shown certain symptoms or signs of DD which draw the attention of caregivers. Consequently, the proportion of confirmed cases in the registry is very high. Although the government never provides the statistics on the proportion of cases excluded after reporting, from our experience of running the EIRRC in the Chia-Yi City (an urban area) and Chia-Yi County (a rural area), we notice that the proportion of cases confirmed by physicians at reporting has been increasing. Therefore, the effect of overestimating

Table 5 Proportion of early reporting of developmental delays in children under 6 years of age by area†

\section{Reported number of cases}

\begin{tabular}{|c|c|c|c|c|c|c|c|}
\hline \multirow[b]{3}{*}{ Year } & & \multirow{3}{*}{$\begin{array}{l}\text { Rural-to-urban proportion } \\
\text { ratio of early reporting } \\
(95 \% \mathrm{Cl})\end{array}$} \\
\hline & \multicolumn{3}{|l|}{ Rural } & \multicolumn{3}{|l|}{ Urban } & \\
\hline & $<3$ years & $<6$ years & $<3$ years $(\%)$ & $<3$ years & <6years & $<3$ years $(\%)$ & \\
\hline 2003 & 1159 & 3016 & 38.4 & 2475 & 7651 & 32.3 & $1.19(1.12 \text { to } 1.26)^{\star}$ \\
\hline 2004 & 1215 & 3499 & 34.7 & 2393 & 6161 & 38.8 & $0.89(0.85 \text { to } 0.94)^{*}$ \\
\hline 2005 & 1140 & 3275 & 34.8 & 2959 & 7031 & 42.1 & $0.83(0.78 \text { to } 0.87)^{*}$ \\
\hline 2006 & 1353 & 3401 & 39.8 & 3415 & 7580 & 45.1 & $0.88(0.84 \text { to } 0.93)^{\star}$ \\
\hline 2007 & 1423 & 3688 & 38.6 & 4294 & 8794 & 48.8 & $0.79(0.75 \text { to } 0.83)^{\star}$ \\
\hline 2008 & 2472 & 4843 & 51.0 & 3578 & 8177 & 43.8 & $1.17(1.12 \text { to } 1.21)^{\star}$ \\
\hline 2009 & 1845 & 4306 & 42.8 & 3646 & 9515 & 38.3 & $1.12(1.07 \text { to } 1.17)^{\star}$ \\
\hline 2010 & 2211 & 5108 & 43.3 & 4152 & 9881 & 42.0 & 1.03 (0.99 to 1.07$)$ \\
\hline 2011 & 1888 & 5074 & 37.2 & 3555 & 8779 & 40.5 & $0.92(0.88 \text { to } 0.96)^{\star}$ \\
\hline 2012 & 2054 & 5829 & 35.2 & 3715 & 9336 & 39.8 & $0.89(0.85 \text { to } 0.92)^{*}$ \\
\hline 2013 & 2271 & 5339 & 42.5 & 4366 & 10124 & 43.1 & 0.99 (0.95 to 1.02$)$ \\
\hline 2014 & 3318 & 6629 & 50.1 & 5175 & 10838 & 47.7 & $1.05(1.02 \text { to } 1.08)^{\star}$ \\
\hline 2015 & 2772 & 5531 & 50.1 & 5712 & 12576 & 45.4 & $1.10(1.07 \text { to } 1.14)^{*}$ \\
\hline 2016 & 2482 & 5591 & 44.4 & 5730 & 13365 & 42.9 & 1.04 (1.00 to 1.07$)$ \\
\hline
\end{tabular}

${ }^{*} \mathrm{P}<0.05$.

†Tainan City and Tainan County were excluded in the analyses due to a reorganisation of administrative regions in 2011. 
the incidence should have been decreasing, and thus would not affect our conclusion of an increasing trend over time.

Since the critical period of treatment for DD is before the child reaches 3 years of age, an early diagnosis is crucial. ${ }^{19}$ Therefore, the Taiwanese government has been promoting the reporting and intervention in cases of children with DD under 3 years of age, ${ }^{213}$ when intervention procedures are most cost-effective. In fact, it is generally believed that the earlier the intervention, the better the prognosis. ${ }^{20}$ Although we observed an increased trend in early reporting from 2003 to 2008, the trend did not persist after 2008. This might indicate that the existing measures of promotion have reached their limits of effectiveness, additional efforts and approaches are required, especially since the proportion of early reporting has never risen beyond $50 \%$.

Previously, we used the data from the national disability registry of Taiwan, a different nationwide source of information than that used in the current study, to conduct a series of studies on major developmental disabilities, including autism spectrum disorders (ASD), intellectual disability, and speech and language disability. ${ }^{17} 1821 \mathrm{We}$ found that the prevalence rates were consistently higher in boys than in girls. Those developmental disabilities are all major risk factors for DD. Therefore, the finding of a higher incidence of DD in boys in the current study is compatible with the findings of our previous studies. Many theories have been proposed to explain the sex difference, including both biological and sociological factors. Biologically, the higher risk in boys is often attributed to hereditary factors such as X-linked conditions. ${ }^{22}{ }^{23}$ The central nervous system of young boys is also found to be more susceptible to damage. ${ }^{22}$ In terms of social factors, in Asian countries, families generally display a male gender preference, and thus pay more attention to boys. ${ }^{22}{ }^{23} \mathrm{In}$ addition, boys are more likely to demonstrate impulsive and aggressive behaviours than girls and therefore are more likely to be referred for diagnosis. ${ }^{23}$

In this study, however, we found that girls had a higher proportion of early reporting than boys. This does not support the theory that the higher level of attention received by boys is a major factor contributing to the higher incidence rate of DD. In fact, a review of literature concluded that boys are more likely to have DD, but when such conditions arise in girls, a more severe form is usually manifest. ${ }^{24}$ Our finding of a higher proportion of early reporting in girls is compatible with this conclusion. Furthermore, as the birth rate has been decreasing in Taiwan, ${ }^{15}$ the difference in the attention received by boys and girls should be decreasing, but we found the sex difference had an increasing trend instead of a decreasing trend. Therefore, we believe biological factors contribute more than social factors to the sex difference in DD in early childhood.

In the preliminary study, we failed to identify the time trend in the sex difference (no significant trend in boy-togirl rate ratio). ${ }^{2}$ The current study has the advantage of a longer follow-up period. In a separate study, which used data from the national disability registry, we found that there was a $497.30 \%$ increase in the prevalence rate of childhood ASD from 2000 to 2011 in Taiwan, which is much higher than the $54.40 \%$ increase in all reported disabilities combined. ${ }^{25}$ In addition, the boy-to-girl ratio of ASD was found to be the highest among the major conditions contributing to DD. ${ }^{47}$ Therefore, we believe the increasing trend in the boy-to-girl incidence rate ratio of DD in Taiwan can largely be attributable to the increasing trend in the number of cases of ASD.

Studies on the differences in DD between rural and urban areas are limited. There are relatively more data on childhood disabilities. The Multiple Indicator Cluster Survey conducted by the United Nations Children's Fund in low/middle-income countries did not observe a consistent result. ${ }^{6}$ Munro reviewed several studies of intellectual disability in the USA and also found results to be inconsistent. ${ }^{23}$ A nationwide study of childhood disability in China, however, found a higher prevalence rate in rural areas, ${ }^{26}$ which is consistent with our finding on DD in this study. Moreover, according to the national disability registry of Taiwan, some major childhood disabilities leading to DD, including intellectual disability and speech and language disability, ${ }^{1821}$ as well as all disabilities combined ${ }^{27}$ were more prevalent in rural areas. While the lower socioeconomic status of rural residents in Taiwan should be a major factor, ${ }^{28}{ }^{29}$ the difference might also be explained by environmental factors such as lower quality of child care, lower parental education, and limited educational and cultural opportunities. ${ }^{52} 30$

The registry of children with DD in Taiwan has some unique features. First of all, it included new cases only, which provides incidence data that are rarely available at the national level and are more reliable for identifying risk factors. ${ }^{31}$ Second, Taiwanese law mandates that cases be reported, and therefore, instances of under-reporting are rare. The registry also has the advantage of a large number (more than 200000 ) of cases. Lastly, the duration of data collection is long, which makes assessing time trends possible.

The major limitation of our study is that the government does not release data on individual cases, and therefore we were unable to conduct more detailed analyses. For example, while we believe the increasing trend in the boy-to-girl incidence rate ratio of DD can largely be attributable to the increasing trend in the number of cases of ASD, we could not perform analyses to verify this. Likewise, we were unable to adjust for the geographical difference while evaluating the effects of sex or age, or study the interaction between sex and geographical difference. In addition, the government does not provide data on the prevalence of $\mathrm{DD}$, and therefore we were unable to study the prevalence of DD directly. Nonetheless, a study that used the National Health Insurance Research Database of Taiwan to estimate the prevalence of DD in children aged $0-6$ years and found that the prevalence gradually increased from $0.16 \%$ to $3.25 \%$ from 1997 to $2008 .{ }^{32}$ Even 
though the case definition was not exactly the same as in the current study and the source of information was different, the study also observed an increasing trend in the annual prevalence and a higher risk in boys than in girls. Geographical differences were not evaluated in that study. Our study is also limited by the range of age under observation. A likely reason of observing a significant increasing trend in the incidence without a remarkable actual increase in the number of cases is that there was a trend of cases being diagnosed (and thus reported) at an earlier age. Although this hypothesis can be tested by evaluating if there was a decreasing trend in the order population, such as 6-12 years old, we did not include cases diagnosed later than 6 years old because the registry only includes cases who had not yet entered the primary school, not all the cases. In the current study, we adopted the 'administrative' data from a national registry which obtains the information on all persons receiving or qualifying for the services, and such an approach was found to generally result in underestimation because it does not include persons who do not receive or not qualify for the services. ${ }^{33}$ However, the administrative data we used have the advantage of providing information on incidence. Although incidence data are preferable to prevalence for investigating risk and aetiology, such data on DD are rare, and therefore epidemiology of DD has generally to be inferred from cross-sectional data. ${ }^{31}$ It has been proposed that incidence data need to be obtained by longitudinal studies from conception or birth to death. ${ }^{31}$ Whereas our study did not apply an active case ascertainment approach such as a house-by-house screening survey, it is a longitudinal study that followed the population from birth and thus can provide the incidence data that some researchers once believed to be unattainable in any population. ${ }^{31}$

\section{CONCLUSIONS}

The incidence rates of young children with DD have been increasing in Taiwan, which is likely to be attributable to improvements in the reporting of cases. The incidence rates are higher in boys than in girls, which is unlikely to be due to more attention received by boys because girls had a higher proportion of early reporting. In addition, the boy-to-girl rate ratio has an increasing trend over the years, and we believe the increasing number of cases of ASD is an important factor. Rural areas had higher incidence than urban areas, which calls for further studies to identify the contributing factors.

\section{Author affiliations}

${ }^{1}$ Department of Physical Medicine and Rehabilitation, Ditmanson Medical Foundation Chia-Yi Christian Hospital, Chia-Yi City, Taiwan

${ }^{2}$ Department of Senior Citizen Service Management, Chia Nan University of Pharmacy and Science, Tainan, Taiwan

${ }^{3}$ Language Education Center and Department of Tourism, Food and Beverage Management, Chang Jung Christian University, Tainan, Taiwan

${ }^{4}$ Department of Occupational and Environmental Medicine, National Cheng Kung University Hospital, Tainan, Taiwan

${ }^{5}$ Occupational Safety, Health and Medicine Research Center, National Cheng Kung University, Tainan, Taiwan
${ }^{6}$ Department of Environmental and Occupational Health, National Cheng Kung University, Tainan, Taiwan

Acknowledgements We would like to thank the Department of Statistics of Ministry of the Interior and the Department of Statistics of the Ministry of the Health and Welfare for providing the registry data and Miss Chao-Hui Weng for her assistance in statistical analysis.

Contributors All the authors approved the contents of the submitted article. $\mathrm{Y}-\mathrm{CT}$ and $\mathrm{H}-\mathrm{RG}$ contributed equally to this work. D-CL and Y-CT conceived and designed the experiments. D-CL and H-RG collected and analysed the data. D-CL and $\mathrm{H}-\mathrm{RG}$ wrote the paper. D-CL, Y-CT and $\mathrm{H}-\mathrm{RG}$ contributed in the final approval of manuscript.

Funding This research was supported by Ditmanson Medical Foundation Chia-Yi Christian Hospital Research Program through grant R105-006.

Competing interests None declared.

Patient consent Not required.

Ethics approval This study has been reviewed and approved by the Institution Review Board of the Ditmanson Medical Foundation Chia-Yi Christian Hospital (CYCH-IRB No: 104016).

Provenance and peer review Not commissioned; externally peer reviewed. Data sharing statement № additional unpublished data.

Open Access This is an Open Access article distributed in accordance with the Creative Commons Attribution Non Commercial (CC BY-NC 4.0) license, which permits others to distribute, remix, adapt, build upon this work non-commercially, and license their derivative works on different terms, provided the original work is properly cited and the use is non-commercial. See: http://creativecommons.org/ licenses/by-nc/4.0/

(c) Article author(s) (or their employer(s) unless otherwise stated in the text of the article) 2018. All rights reserved. No commercial use is permitted unless otherwise expressly granted.

\section{REFERENCES}

1. First LR, Palfrey JS. The infant or young child with developmental delay. N Engl J Med 1994;330:478-83.

2. Lai D-C, Tseng Y-C, Guo H-R. Gender and geographic differences in developmental delays among young children: analysis of the data from the national registry in Taiwan. Res Dev Disabil 2011;32:63-9.

3. Stich HL, Baune BT, Caniato RN, et al. Individual development of preschool children-prevalences and determinants of delays in Germany: a cross-sectional study in Southern Bavaria. BMC Pediatr 2012;12:188.

4. Boyle CA, Boulet S, Schieve LA, et al. Trends in the prevalence of developmental disabilities in US children, 1997-2008. Pediatrics 2011;127:1034-42.

5. Robinson LR, Holbrook JR, Bitsko RH, et al. Differences in health care, family, and community factors associated with mental, behavioral, and developmental disorders among children aged 2-8 years in rural and urban areas - United States, 2011-2012. MMWR Surveill Summ 2017;66:1-11.

6. Durkin M, Gottlieb C, Maenner M, et al. Monitoring child disability in developing countries: results from the Multiple Indicator Cluster Surveys. New York and Madison: UNICEF and University of Wisconsin School of Medicine and Public Health, 2008.

7. The Children Welfare Law. The whole modified enacted text of 54 articles promulgated by President Wha-Jong (1) Yi-Tzi No.0475: Taiwan Government, 1993.

8. The Children and Youth Welfare Law. The whole text of 75 articles promulgated by President Wha-Jong (1) Yi-Tzi No. 09200096700: Taiwan Government, 2003.

9. The Enforcement Rules of the Children and Youth Welfare Law. The whole text of 24 articles promulgated by Taiwan Ministry of the Interior No.0930093663: Taiwan Government, 2004.

10. Child Welfare Bureau, Ministry of the Interior. Manual of Early Intervention Services. Taichung, Taiwan: Child Welfare Bureau, Ministry of the Interior, 2007.

11. Liao H-F, Cheng L-Y, Hsieh W-S, et al. Selecting a cutoff point for a developmental screening test based on overall diagnostic indices and total expected utilities of professional preferences. $J$ Formos Med Assoc 2010;109:209-18. 
12. Ministry of Health and Welfare. Statistical Year Book of Welfare: 2.5.4 Reporting Number of Early Intervention Services for Developmentallydelayed Children. Taipei, Taiwan: Department of Statistics, Ministry of Health and Welfare, 2017.

13. Huang P-H. The development and current situation of the early intervention for children with developmental delay in Taiwan. Int $J$ Child Care Educ Policy 2007;1:45-58.

14. Ministry of the Interior. Monthly Bulletin of Interior Statistics: 1.7 Population for Township and District and by Urban Area. Taipei, Taiwan: Department of Statistics, Ministry of the Interior, 2010.

15. Ministry of the Interior. Monthly Bulletin of Interior Statistics: 1.11 Population by Single Year of Age and Median Age. Taipei, Taiwan: Department of Statistics, Ministry of the Interior, 2017.

16. Murphy CC, Boyle C, Schendel D, et al. Epidemiology of mental retardation in children. Ment Retard Dev Disabil Res Rev 1998;4:6-13.

17. Lai D-C, Tseng Y-C, Hou Y-M, et al. Gender and geographic differences in the prevalence of autism spectrum disorders in children: analysis of data from the national disability registry of Taiwan. Res Dev Disabil 2012;33:909-15.

18. Lai D-C, Tseng Y-C, Hou Y-M, et al. Gender and geographic differences in the prevalence of intellectual disability in children: analysis of data from the national disability registry of Taiwan. Res Dev Disabil 2012;33:2301-7.

19. Grantham-McGregor S, Cheung YB, Cueto S, et al. Developmental potential in the first 5 years for children in developing countries. Lancet 2007;369:60-70.

20. Lai D-C, Chiang C-H, Hou Y-M, et al. Predictors of effectiveness of early intervention on children with intellectual disability: a retrospective cohort study. BMC Pediatr 2014;14:170.

21. Tseng Y-C, Lai D-C, Guo H-R. Gender and geographic differences in the prevalence of reportable childhood speech and language disability in Taiwan. Res Dev Disabil 2015;40:11-18.
22. Leonard $\mathrm{H}$, Wen $\mathrm{X}$. The epidemiology of mental retardation: challenges and opportunities in the new millennium. Ment Retard Dev Disabil Res Rev 2002;8:117-34.

23. Munro JD. Epidemiology and the extent of mental retardation. Psychiatr Clin North Am 1986;9:591-624.

24. Eme RF. Selective females affliction in the developmental disorders of childhood: a literature review. J Clin Child Psychol 1992;21:354-64.

25. Lai D-C, Tseng Y-C, Guo H-R. Trends in the prevalence of childhood disability: analysis of data from the national disability registry of Taiwan, 2000-2011. Res Dev Disabil 2013;34:3766-72.

26. Zhang H, Bo SH, Zhang XT, et al. Sampling survey of disability in 0-6 year-old children in China. Biomed Environ Sci 2006;19:380.

27. Ministry of Health and Welfare. Statistical Yearbook of Welfare: 2.3.6 The Disabled Population by Locality and Age. Taipei, Taiwan: Department of Statistics, Ministry of Health and Welfare, 2017.

28. Emerson E. Poverty and people with intellectual disabilities. Ment Retard Dev Disabil Res Rev 2007;13:107-13.

29. Leonard H, Petterson B, De Klerk N, et al. Association of sociodemographic characteristics of children with intellectual disability in Western Australia. Soc Sci Med 2005;60:1499-513.

30. Roeleveld N, Zielhuis GA, Gabreëls F. The prevalence of mental retardation: a critical review of recent literature. Dev Med Child Neurol 1997;39:125-32.

31. Durkin M. The epidemiology of developmental disabilities in lowincome countries. Ment Retard Dev Disabil Res Rev 2002;8:206-11.

32. Kuo HT, Muo $\mathrm{CH}$, Chang YT, et al. Change in prevalence status for children with developmental delay in Taiwan: a nationwide population-based retrospective study. Neuropsychiatr Dis Treat 2015:11:1541-7.

33. Larson SA, Lakin KC, Anderson L, et al. Prevalence of mental retardation and developmental disabilities: estimates from the 1994/1995 National Health Interview Survey Disability Supplements. Am J Ment Retard 2001;106:231-52. 